\title{
Evidence for a cytoplasmic microprocessor of pri-miRNAs
}

\author{
JILLIAN S. SHAPIRO, RYAN A. LANGLOIS, ALISSA M. PHAM, and BENJAMIN R. TENOEVER ${ }^{\mathbf{1}}$
}

Department of Microbiology, Mount Sinai School of Medicine, New York, New York 10029, USA

\begin{abstract}
microRNAs (miRNAs) represent a class of noncoding RNAs that fine-tune gene expression through post-transcriptional silencing. While miRNA biogenesis occurs in a stepwise fashion, initiated by the nuclear microprocessor, rare noncanonical miRNAs have also been identified. Here we characterize the molecular components and unique attributes associated with the processing of virus-derived cytoplasmic primary miRNAs (c-pri-miRNAs). RNA in situ hybridization and inhibition of cellular division demonstrated a complete lack of nuclear involvement in c-pri-miRNA cleavage while genetic studies revealed that maturation still relied on the canonical nuclear RNase III enzyme, Drosha. The involvement of Drosha was mediated by a dramatic relocalization to the cytoplasm following virus infection. Deep sequencing analyses revealed that the cytoplasmic localization of Drosha does not impact the endogenous miRNA landscape during infection, despite allowing for robust synthesis of virus-derived miRNAs in the cytoplasm. Taken together, this research describes a unique function for Drosha in the processing of highly structured cytoplasmic RNAs in the context of virus infection.
\end{abstract}

Keywords: DGCR8; Drosha translocation; virus; Argonaute

\section{INTRODUCTION}

microRNAs (miRNA) are noncoding, regulatory small RNAs of $\sim 22$ nucleotides (nt) in length which are thought to fine-tune gene expression in a myriad of cellular processes (Kim et al. 2009). Aberrant miRNA processing and expression is often related to human diseases such as cancer or abnormal development, demonstrating the vast posttranscriptional control these small RNAs are capable of exerting on the cell (Bartel 2009). Canonically, miRNAs are transcribed in an RNA polymerase II-dependent fashion to produce a primary-miRNA transcript (pri-miRNA), consisting of one or more miRNA-containing stem-loop structures, the majority of which are embedded in introns (Lagos-Quintana et al. 2001; Lim et al. 2003; Cai et al. 2004; Lee et al. 2004). The pri-miRNA secondary structure is recognized by the nuclear microprocessor, which consists of the ribonuclease (RNase) III enzyme Drosha and the essential double-stranded RNA (dsRNA) binding protein DiGeorge syndrome critical region gene 8 (DGCR8) (Denli et al. 2004; Gregory et al. 2004; Han et al. 2006). The microprocessor generates an $\sim 60-70$-nt precursor miRNA (pre-miRNA) containing a 2-nt-3' overhang, a characteristic

\footnotetext{
${ }^{1}$ Corresponding author

E-mail benjamin.tenoever@mssm.edu

Article published online ahead of print. Article and publication date are at http://www.rnajournal.org/cgi/doi/10.1261/rna.032268.112.
}

of RNase III-mediated processing. Subsequently, Exportin-5 (Exp5) translocates the pre-miRNA into the cytoplasm in a Ran-GTP-dependent fashion (Yi et al. 2003; Bohnsack et al. 2004; Lund et al. 2004).

Once in the cytoplasm, a second RNase III enzyme, Dicer, recognizes the distinct terminus of the pre-miRNA and cleaves $\sim 22$ nt from the end, generating a duplex RNA flanked by 2-nt-3' overhangs (Bernstein et al. 2001; Grishok et al. 2001; Hutvagner et al. 2001; Ketting et al. 2001; Park et al. 2011). The efficiency of Dicer processing is enhanced with the aid of the dsRNA binding proteins Taractivating RNA binding protein 2 (TRBP2) and/or a TRBP2 homolog, PKR activating protein (PACT) (Chendrimada et al. 2005; Haase et al. 2005; Lee et al. 2006). Based on the relative thermodynamic stability at the ends of the duplex, one strand, denoted the mature strand, is selected to associate with an Argonaute (AGO1-4) protein, a core component of the RNA induced silencing complex (RISC), while the other strand (star strand) is degraded (Khvorova et al. 2003; Schwarz et al. 2003; Czech and Hannon 2011). Once loaded into RISC, the miRNA sequence serves as a guide to identify target mRNA through partial complementarity between the mRNA and the miRNA seed sequence (nucleotide 2-8 from the $5^{\prime}$ end of the mature miRNA), resulting in translational repression and/or mRNA deadenylation in a process collectively termed post-transcriptional silencing (PTS) (Filipowicz et al. 2008; Bartel 2009; Bazzini et al. 2012). 
With the advent of high throughput sequencing technology, many noncanonical miRNA biogenesis mechanisms have been uncovered (Okamura et al. 2007; Ruby et al. 2007; Babiarz et al. 2008). While rare, the majority of noncanonical miRNAs bypass the necessity for the microprocessor but still require Dicer for proper duplex formation. The most common examples of this type of noncanonical miRNA biogenesis are mirtrons, in which splicing and debranching result in a transcript that can refold to form a canonical pre-miRNA (Okamura et al. 2007; Ruby et al. 2007). In contrast, a notable exception to Dicer-dependent, canonical processing is miR-451, an essential miRNA involved in erythropoiesis (Cheloufi et al. 2010; Cifuentes et al. 2010; Yang et al. 2010). Synthesis of miR-451 utilizes the catalytic activity of AGO2, in conjunction with an asof-yet unknown nuclease, to process the pre-miRNA in the cytoplasm (Cheloufi et al. 2010; Cifuentes et al. 2010; Yang et al. 2010).

Another example of noncanonical miRNA biogenesis was identified with the recent discovery that RNA viruses of cytoplasmic origin can be engineered to produce functional miRNAs (Rouha et al. 2010; Shapiro et al. 2010; Langlois et al. 2012). Initial characterization of these transcripts demonstrated that virus-derived cytoplasmic pri-miRNAs (c-pri-miRNAs) are processed in a manner that is independent of the canonical microprocessor, but still require Dicer. Here we probe the cellular requirements for c-pri-miRNA synthesis and define the structural constraints and attributes associated with processing utilizing a collection of miRNAproducing, recombinant Sindbis viruses (rSINVs). We demonstrate c-pri-miRNA processing occurs exclusively in the cytoplasm and results in the unique redistribution of Drosha in a virus-specific manner.

\section{RESULTS AND DISCUSSION}

\section{Cytoplasmic processing of pri- miRNAs is independent of hairpin structure and transcript positioning}

As our analyses of c-pri-miRNA processing were limited to rSINV expressing mmu-miR-124-2 (rSINV124), we engineered a second rSINV expressing mmu-miR-122 (rSINV122), a liver-specific miRNA (Lagos-Quintana et al. 2002), using an identical strategy. Virus rescue of rSINV122 and subsequent infection in fibroblasts at a multiplicity of infection (MOI) of 1 revealed robust expression of the 22-nt miR-122 at $16 \mathrm{~h}$ post-infection (hpi), comparable to the expression of virus-derived miR-124 (Fig. 1A). These data demonstrate that cytoplasmic processing of miRNAs is not unique to the structure or sequence of the c-pri-miRNA.

Given that a large proportion of canonical transcripts generate multiple miRNAs (Lee et al. 2002), we next examined whether this activity could be recapitulated in the cytoplasm. To this end, we engineered a rSINV encoding a single transcript composed of the miR-124 hairpin $230 \mathrm{nt}$ downstream from the miR-122 locus (a virus herein referred to as rSINVdbl). Virus rescue and subsequent characterization revealed both mature miR-122 and miR-124 could be produced from the rSINVdbl transcript, comparable to rSINVs encoding only a single miRNA (Fig. 1A, lanes 5 and 10, respectively; Supplemental Fig. S1A). Although the c-pri-miRNA derived from rSINVdbl is $500 \mathrm{nt}$ greater in length, as compared with rSINV124 or rSINV122, the resolution of the small RNA Northern polyacrylamide gel does not permit differential migration patterns. However, while the levels of c-pri- and mature miR-122 were comparable between rSINV122 and rSINVdbl, the latter virus resulted in a significant decrease in miR-124 as compared with rSINV124, presumably as a result of its $3^{\prime}$ proximal position. Interestingly, the absence of any intermediate products suggests that the c-pri-miRNAs are rapidly processed or degraded.

To determine whether miR-122 and miR-124 were equally loaded into RISC, independent of transcript context,
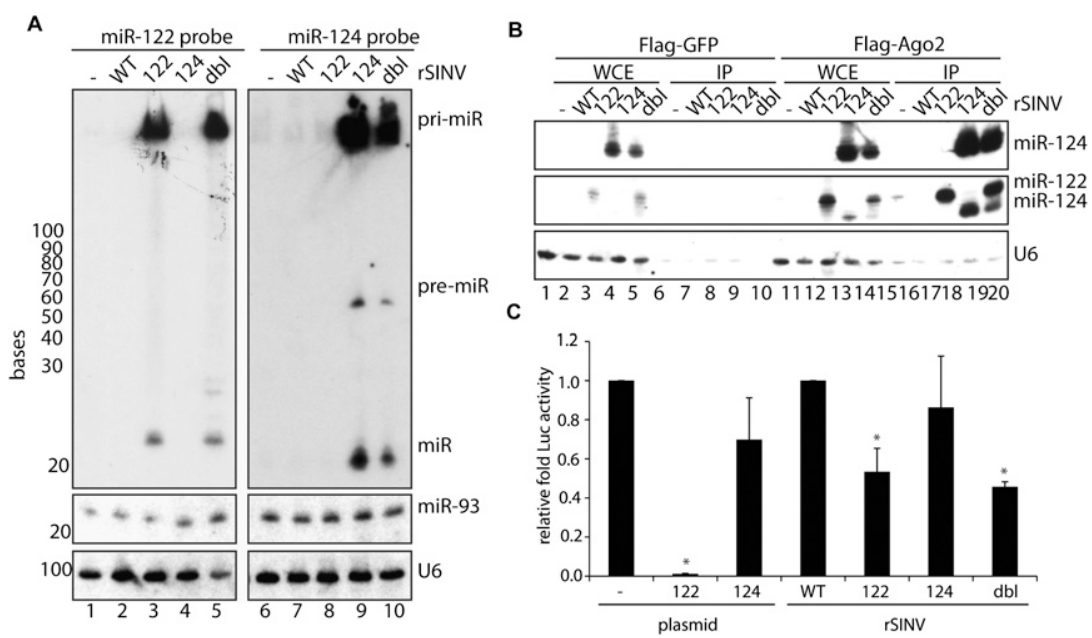

FIGURE 1. Cytoplasmic-mediated miRNA biogenesis. (A) Small RNA Northern blot of BHKs mock-treated or infected for $16 \mathrm{~h}$ with rSINV (WT) or rSINV expressing miR-122 (122), miR-124 (124), or tandem miR-122/miR-124 (dbl). RNA was probed for miR-122 (top left), miR-124 (top right), miR-93 (middle), and U6 (bottom). (B) IP of BHKs transfected with Flag-epitope tagged GFP or AGO2 and subsequently infected with viruses analyzed in $A$ at an MOI of 2 for $16 \mathrm{~h}$. Small RNA Northern blot of IP probed with miR-124 (top), miR-122 (middle) or U6 (bottom). Residual miR-124 signal remains in blot probed with miR-122 (middle panel). (C) Luciferase assay utilizing a secreted Gaussia luciferase containing miR-122 target sites expressed in BHKs transfected with a plasmid expressing a scrambled hairpin (-), miR-122 (plasmid, 122), or miR-124 (plasmid, 124) or infected with WT, miR-122-expressing (122), miR-124-expressing (124), or dbl-expressing (dbl) rSINVs at an MOI of 3 for $8 \mathrm{~h}$. Samples were analyzed in triplicate, and two-tailed, unpaired Student's $T$-test was performed. $\left(^{*}\right) P<0.05$. 
Flag-epitope tagged AGO2 and GFP immunoprecipitations (IPs) were performed following rSINV infections at an MOI of 2 for $16 \mathrm{~h}$ (Fig. 1B). While GFP IPs demonstrated no association with miR-122 or with miR-124, AGO2 associated with both miRNAs, regardless of transcript source. However, in agreement with the initial rSINVdbl characterization (Fig. 1A), the decreased production of miR-124 was also mirrored in its association with AGO2 (Fig. 1B; Supplemental Fig. S1B, cf. lanes 14,15 and 19,20) and in its capacity to silence Gaussia luciferase containing four perfect miR122 target sites (GLuc122T) (Fig. 1C).

\section{Processing of c-pri-miRNAs is independent of cell division and nuclear access}

The ability to produce miRNAs from a virus-generated, 5' -capped and 3'-polyadenylated c-pri-miRNA transcript could result from the breakdown of the nuclear envelope during cell division, thereby providing access to the canonical microprocessor. To address a requirement for access to nuclear-localized components, cell cycle was inhibited by serum starvation to ascertain whether this would abolish cleavage of c-pri-miRNA. To monitor arrest, cells were treated with carboxyfluorescein succinimidyl ester (CFSE) and analyzed by flow cytometry to examine compound dilution as a result of cell division. Between 24 and $48 \mathrm{~h}$ post-serum deprivation, sustained levels of CFSE, as compared with control cells (CTRL), confirmed a complete block in cell division (Fig. 2A). As such, 24 h postserum starvation cells were mock-treated or infected at an MOI of 5 with rSINV124. As indicated by levels of virus-derived pri-miR-124 and -nsP1, rSINV124 infection of nondividing cells resulted in reduced replication (Fig. 2B and Supplemental Fig. S1C, respectively). However, the relative levels of cytoplasmic miRNA generated from rSINV124 were not impacted, as the ratio of conversion of c-pri-miR-124 to mature miR-124 $(\sim 1: 1.25$, respectively) was sustained in the absence of cell division (Fig. 2B; Supplemental Table S1). These data strongly suggest that, while cell division influences virus replication, it is not required for cytoplasmic-mediated miRNA synthesis.

D
In an effort to corroborate the localization of c-primiRNA, we performed RNA in situ hybridization in the context of virus-mediated cytoplasmic- or nuclear-derived primary transcripts. To this end, cytoplasmic replication of rSINV124 was compared with the nuclear replication of an influenza A virus engineered to produce miR-124 (IAV124) (Varble et al. 2010). RNA in situ hybridization utilizing a probe designed to selectively hybridize to pri-miR-124 (Fig. 2C) demonstrated nuclear accumulation in IAV124-infected
A
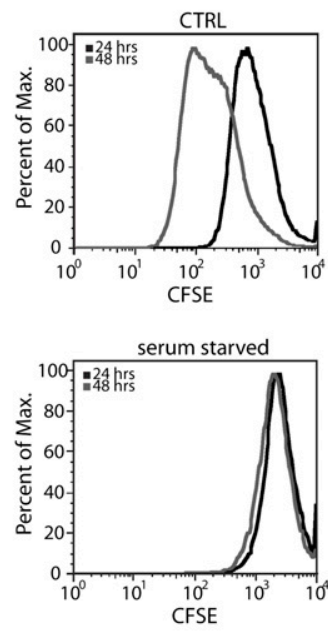

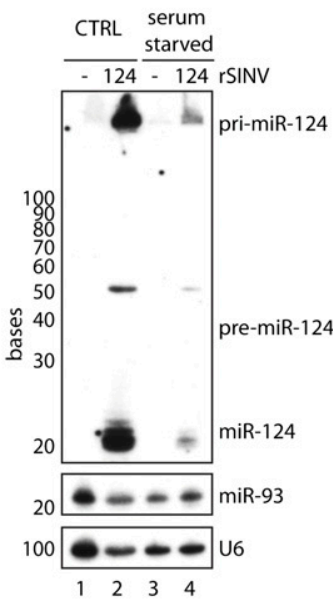

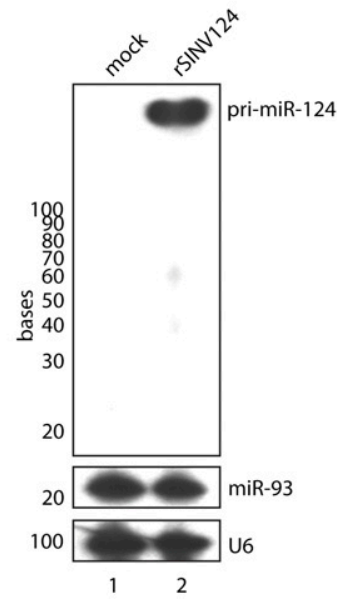
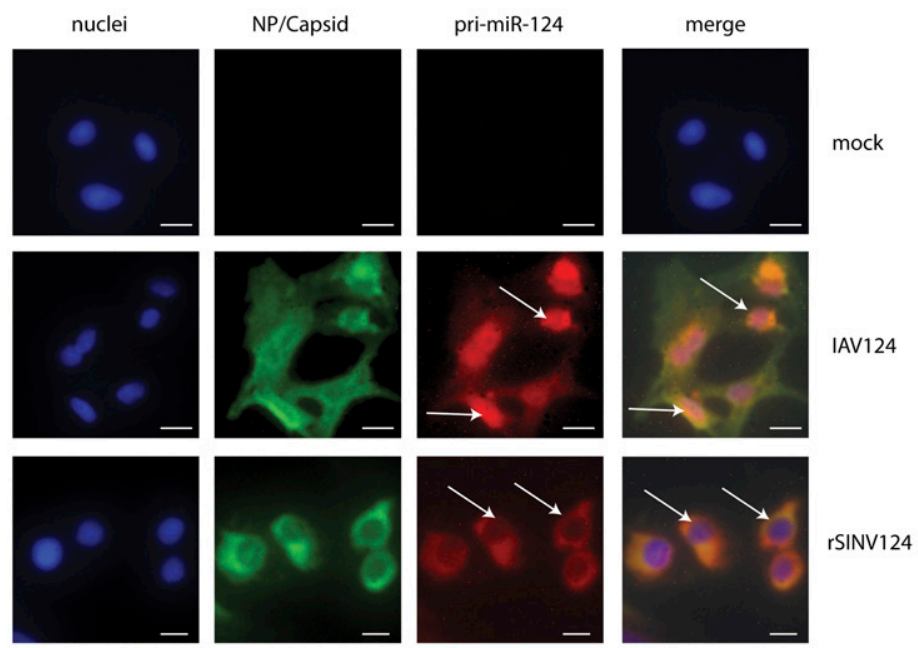

FIGURE 2. Cytoplasmic generation of a miRNA does not require cell division nor nuclear access. (A) MEFs were incubated with $10 \mu \mathrm{M}$ CFSE, cultured with (top, CTRL) or without (bottom, serum starved) 10\% serum, and were fixed and analyzed by FACS at 24 and 48 h postserum starvation. $(B)$ MEFs treated as in $A$ were additionally mock-treated or infected with rSINV124 (MOI $=5$ ) for $16 \mathrm{~h}$ and subsequently analyzed via small RNA Northern blot for miR-124 (top), miR-93 (middle), and U6 (bottom). (C) Small RNA Northern blot of mocktreated and rSINV124-infected BHKs probed with pri-miR-124 (top), miR-93 (middle), and U6 (bottom). (D) Microscopy of BHKs mock-treated (top) or infected with IAV124 (MOI = 10) (middle) or with rSINV124 (MOI = 3) (bottom) for $16 \mathrm{~h}$. Cells stained for cell nuclei (first column, blue), IAV-specific NP and SINV-specific capsid (second column, green), and primiR-124 (third column, red). All images merged (far right column). Scale bar, $10 \mu \mathrm{m}$. Arrows point to nuclear localization of pri-miR-124 upon IAV124 infection (middle row) and to lack of nuclear signal upon rSINV124 infection (bottom row). 
cells, as expected for canonical processing (Fig. 2D, middle). In contrast, infection with rSINV124, despite causing cell rounding, clearly demonstrates an absence of nuclear pri-miR-124 signal and an abundance of the transcript in the cytoplasm (Fig. 2D, bottom). These data confirm that c-pri-miRNA are localized to, and remain within, the cytoplasm throughout infection and during the process of miRNA biogenesis.

\section{Genetic requirements for processing of c-pri-miRNAs}

In an effort to determine whether the core components of the nuclear microprocessor were required for c-pri-miRNA cleavage, despite the disparity in cellular localization, we characterized rSINV124-derived miR-124 synthesis in DGCR8- and Drosha-deficient cells (Fig. 3). As these fibroblast-derived cell lines are conditional knockouts, cells were initially treated with replication-deficient Adenovirus vectors expressing either green fluorescent protein (GFP) or a GFP-Cre recombinase fusion protein (GFP and Cre, respectively). Six days post-treatment of $D g c r 8^{f l / f l}$ and Rnasen $^{f l f l}$ (the gene encoding Drosha) cells, we could confirm complete loss of endogenous, canonical miR-93 (which normally maintains concentrations of 10,000 copies/cell) (Fig. 3; Tye 1999). Following confirmation of DGCR8 and Drosha disruption, we infected with rSINV124 for $16 \mathrm{~h}$ at an MOI of 5 and analyzed miR-124 synthesis (Fig. 3; Supplemental Fig. S1D). Interestingly, despite the discrepancy between the cytoplasmic localization of the

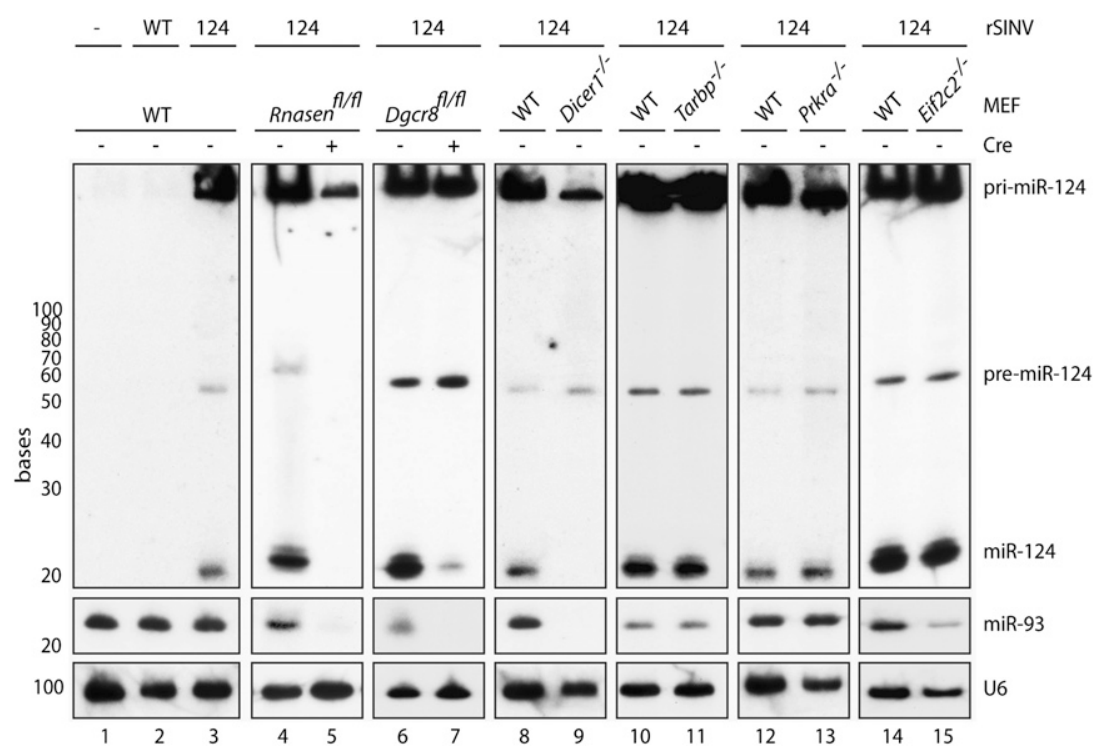

FIGURE 3. Cytoplasmic requirements for processing of pri-miRNAs. Northern blot depicting WT MEFs or MEFs deficient in Drosha, DGCR8, Dicer, TRBP2, PACT, or AGO2 (Rnasen, Dgcr8, Dicer1, Tarbp, Prkra, or Eif2c2, respectively) mock-treated or infected with WT-rSINV or rSINV124 (MOI = 5 for Drosha and DGCR8-deficient cells; MOI = 1 for Dicer-, TRBP2-, PACT-, and AGO2-deficient cells; 16 h for all samples) and RNA was analyzed via small RNA Northern blot probed for miR-124 (top), miR-93 (middle), and U6 (bottom).
c-pri-miRNA and the nuclear localization of the canonical microprocessor, loss of Drosha resulted in complete ablation of virus-derived pre- and mature miR-124 (Fig. 3, lanes 4,5; Supplemental Table S2).

Surprisingly, in contrast to Drosha dependency, loss of DGCR8 only altered the accumulation of mature miR-124 while having no impact on the conversion of c-pri-miRNA to pre-miRNA, making its involvement in cytoplasmic processing difficult to discern (Fig. 3, lanes 6,7; Supplemental Table S2). The selective decrease in mature miRNA suggests that, while DGCR8 is not required for Droshamediated cleavage, it may be essential for its accuracy. In support of this hypothesis, loss of DGCR8 does result in an accumulation of pre-miR-124, suggesting this RNA may no longer be an optimal Dicer substrate. Alternatively, the cytoplasmic microprocessor may be DGCR8-independent and the phenotype due to an indirect effect on the cell's small RNA machinery following the loss of endogenous miRNAs. Future work will be needed to discern between these two possibilities.

In an effort to determine whether any of the other known miRNA biogenesis components were required for c-primiRNA processing, we additionally infected cells lacking Dicer, TRBP2, or PACT (encoded by Dicer1, Tarbp, and Prkra genes, respectively) with rSINV124 (Fig. 3, lanes 8-13; Supplemental Table S2). Northern blot analysis from rSINV124-infected Dicer1 knockout cells demonstrated abundant levels of c-pri-miR-124 and the $\sim 60$-nt premiRNA, with only mature miR-124 absent (Fig. 3, lane 9; Supplemental Table S2). The levels and size of pre-miR-124 were comparable to that produced in rSINV124-infected WT cells, suggesting that Dicer is not involved in cleavage of the c-pri-miRNA into pre-miRNA. In the absence of TRBP2 and of PACT, the levels of all three miRNA species (c-pri-, pre-, and mature) remained unchanged (Fig. 3, lanes 10-13; Supplemental Table S2). Given the shared $42 \%$ amino acid homology between TRBP2 and PACT (Haase et al. 2005), these results suggest these dsRNA binding proteins are not essential, or are functionally redundant, with regards to Drosha- and/or Dicer-mediated processing of c-pri-miRNAs.

To conclude our genetic characterization of c-pri-miRNA processing, we investigated a requirement for $\mathrm{AGO} 2$ (encoded by the Eif2c2 gene). Given previous results demonstrating the role of AGO2 in the generation of miR-451 (Cheloufi et al. 2010; Cifuentes et al. 2010; Yang et al. 2010), we investigated whether AGO2 had a role in processing, 
despite the fact that miR-124 does not conform to the structural requirements for AGO2-dependent cleavage (Cheloufi et al. 2010; Cifuentes et al. 2010; Yang et al. 2010). To this end, we infected cells deficient in AGO2 with rSINV124 at an MOI of 1 for $16 \mathrm{~h}$ to compare virus-derived cytoplasmic miR-124 synthesis with that of infected WT cells. These data demonstrated no alteration in pre- or mature miR-124 production (Fig. 3, lane 15; Supplemental Table S2). Taken together, these results implicate the RNase III proteins, Dicer and Drosha, and possibly the dsRNA binding protein DGCR8, in the accurate processing of c-pri-miRNAs.

\section{rSINV infection recruits Drosha to the cytoplasm without altering the endogenous miRNA profile}

with rSINV-124 (Fig. 4C; Supplemental Table S3). These analyses demonstrated that, after $24 \mathrm{~h}$ of infection, rSINV124-derived miR-124 accounted for $4.3 \%$ of the total miRNAs within the cell, reaching estimated concentrations ranging up to 55,000 copies/cell (Fig. 4C; Supplemental Table S3). Furthermore, neither infection with SINV nor the overexpression of a c-pri-miRNA resulted in aberrations in the endogenous miRNA profile, presumably due to the fact that the half life of most miRNAs is $>24 \mathrm{~h}$ (Baccarini et al. 2011; Gantier et al. 2011). Taken together, these data suggest that neither the relocalization of Drosha, nor overproduction and subsequent processing of a c-pri-miRNA, impact the cellular miRNA landscape.
While Dicer dependency of c-pri-miRNA processing was anticipated, the role of Drosha in cleavage of a cytoplasmiclocalized RNA transcript is enigmatic. In this regard, it is noteworthy that Drosha is thought to shuttle to the nucleus in a phosphorylation-dependent manner (Tang et al. 2010). As such, we next sought to ascertain whether the subcellular localization of Drosha is altered in the presence of virus infection and/or when the hairpin substrate is confined to the cytoplasm. To this end, we performed immunohistochemistry against endogenous Drosha in fibroblasts mock-treated or infected with rSINV or rSINV124. Surprisingly, in contrast to nuclear Drosha in mock-treated cells, infection with rSINV or rSINV124 resulted in a dramatic redistribution of the protein to the cytoplasm (Fig. 4A).

Given the loss of nuclear Drosha upon infection with rSINVs, we next sought to determine whether this had an impact on the endogenous miRNA profile. To this end, we deep sequenced the small RNA fraction from fibroblasts mock-treated or infected with rSINV for $24 \mathrm{~h}$. Linear regression analysis of the levels of all annotated miRNAs in mock-treated cells versus rSINV-infected cells indicated that the miRNA profile remained largely unchanged in the presence of virus infection, despite the high levels of Drosha within the cytoplasm (Fig. 4B; Supplemental Table S3). Furthermore, to ascertain whether overexpression and subsequent processing of a pri-miRNA in the cytoplasm impacted the endogenous miRNA profile, we performed a similar analysis

\section{A}
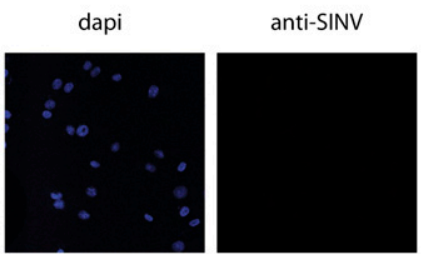

anti-drosha
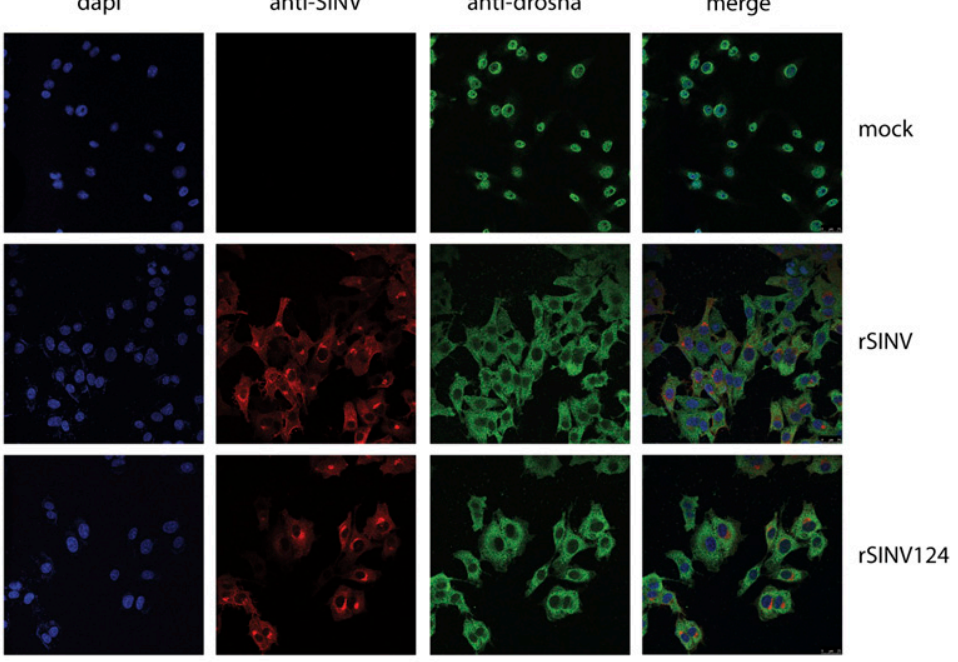

B

C
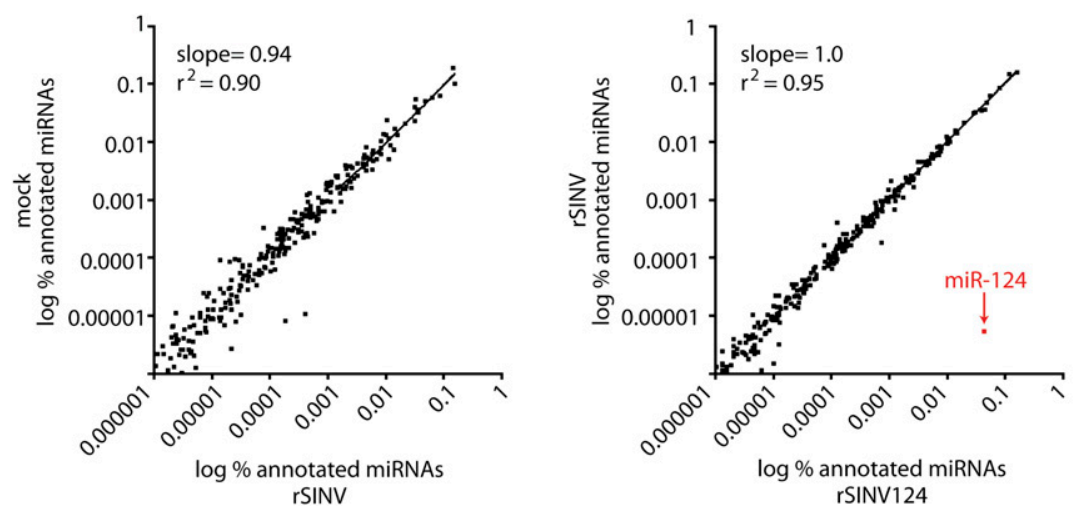

FIGURE 4. Virus-induced subcellular redistribution of Drosha. (A) Confocal microscopy of BHKs mock-treated (top) or infected with rSINV (middle) or rSINV124 (bottom) at an MOI of 10 for $5 \mathrm{~h}$. Cells stained for dapi (blue, first column), SINV-specific capsid (red, second column), and Drosha (green, third column). All images merged (far right). Scale, $25 \mu \mathrm{m} .(B)$ Comparison of miRNA profile in mock-treated MEFs and MEFs infected with rSINV at an MOI of 2 for $24 \mathrm{~h}$. Data represent the \% representation for each annotated miRNA. $(C)$ Comparison of miRNA profile in MEFs infected with rSINV or with rSINV124 at an MOI of 2 for $24 \mathrm{~h}$. Data represent the \% representation for each annotated miRNA. 


\section{CONCLUSIONS}

There are multiple means in which cells generate functional miRNAs, including nuclear canonical biogenesis as well as examples of Drosha- or Dicer-independent events (Berezikov et al. 2007; Ruby et al. 2007; Cheloufi et al. 2010; Cifuentes et al. 2010; Yang et al. 2010). We, and others, have demonstrated processing of pri-miRNAs derived from the cytoplasm (Rouha et al. 2010; Shapiro et al. 2010; Langlois et al. 2012). However, the mechanism and characteristics of cytoplasmic biogenesis have not been thoroughly elucidated. Herein, we demonstrate that various c-pri-miRNAs are amenable to processing within the cytoplasm to produce AGO2-associated, functional miRNAs (Fig. 1). Furthermore, inhibition of cell cycle and RNA in situ hybridization both corroborated that processing was independent of nuclear access (Fig. 2). Additionally, through the utilization of knockout mammalian cell lines, we conclusively demonstrate Drosha and Dicer dependency in c-pri-miRNA processing (Fig. 3).

In examining the auxiliary dsRNA binding proteins previously implicated in canonical processing, we excluded a role for all components with the exception of DGCR8, which resulted in an unusual phenotype. We found that, in the absence of DGCR8, cleavage of the c-pri-miRNA continues to occur, although overall miRNA biogenesis is impaired (Fig. 3). As previously stated, this could be the result of inaccurate processing of pri- to pre-miRNAs. This however raises the issue as to why DGCR8 knockout cells do not accumulate poorly processed pre-miRNAs (Babiarz et al. 2008, 2011). One possible explanation for this observation is that the mode of nuclear export is intrinsically associated with transcript-specific activities (Zeng and Cullen 2004). As loss of DGCR8 would prevent Exp5dependent translocation of these poorly processed premiRNAs, these transcripts would be rapidly subjected to degradation through nonsense-mediated decay (Isken and Maquat 2007). Interestingly, in this model, the accumulation of pre-miR-124 observed in DGCR8 knockout cells would implicate this dsRNA binding protein as a component of the cytoplasmic microprocessor and would confirm its nuclear-independent biogenesis. In contrast to this model, given that Drosha has never been shown to function in the absence of DGCR8, it remains possible that c-pri-miRNA processing involves an, as-of-yet, uncharacterized, perhaps virus-inducible, dsRNA binding protein (Saunders and Barber 2003). In this context, the decrease in miR-124 observed in DGCR8 null cells (Fig. 3) could simply be an indirect phenotype caused by the loss of endogenous miRNAs. Future work will be required to distinguish between these models.

Regardless of the role of DGCR8, this work ascribes two separate functions for Drosha: (1) the canonical microprocessor and (2) the virus-induced, cleavage of cytoplasmic structured mRNAs. The dramatic relocalization of Drosha upon virus infection makes it tempting to speculate its involvement as a virus restriction factor, independent of miRNA biogenesis. It is noteworthy that Drosha has already been characterized to act directly on mRNA (Han et al. 2009; Kadener et al. 2009). Perhaps Drosha represents a vestigial remnant of the small RNA-mediated defense mechanism that has been evolutionarily retained from plants, worms, and flies and repurposed in the cleavage of mRNA during times of cellular stress. Clearly, future work examining the role of Drosha in infected cells will be necessary to determine the full scope of this physiological activity.

\section{MATERIALS AND METHODS}

\section{Vector design for cytoplasmic miRNA synthesis}

Generation of rSINV expressing miR-124 has been described elsewhere (Shapiro et al. 2010; Varble et al. 2010). Similarly, rSINV122 was generated by cloning the mmu-miR-122 locus (chr18:65, $408,015-65,409,080$ ) into rSINV as previously described (Shapiro et al. 2010). rSINVdbl was generated by cloning $230 \mathrm{nt}$ upstream of the mmu-miR-124 stem-loop of the rSINV124 genome. Viruses were rescued as previously described (Shapiro et al. 2010).

\section{Virus infections}

rSINV and IAV infections were performed at MOIs of 1 and 10, respectively, unless otherwise noted. Virus was inoculated into indicated cell lines containing serum-free DMEM for $1 \mathrm{~h}$. Inoculum was then removed and replaced with complete medium for indicated times.

\section{Cell culture}

Knockout cells used in this study are all described elsewhere (Patel and Sen 1998; Zhong et al. 1999; O'Carroll et al. 2007; Babiarz et al. 2008; Chong et al. 2010; Perez et al. 2010). All cells were cultured in DMEM supplemented with 10\% FBS and penicillin/ streptomycin unless otherwise indicated. Floxed cells were infected with Adenovirus expressing GFP or GFP/Cre (vector biolabs \#1060 and \#1700, respectively) at an MOI of 500 and subsequently treated six days post-Adenovirus infection as described. For serum starvation, cells were washed and incubated with serum free media for $24 \mathrm{~h}$ prior to infection. To confirm loss of cell division, cells were incubated with $10 \mu \mathrm{m}$ CFSE (molecular probes) for $10 \mathrm{~min}$ at $37^{\circ} \mathrm{C}$. CFSE was quenched with $25 \% \mathrm{BSA}$, washed, and replated in DMEM with or without $10 \%$ serum. At 24 and 48 h post-CFSE labeling, cells were fixed (BD FACS lysis solution), run on a FACS Calibur (BD), and analyzed using Flojo (Treestar).

\section{Small RNA Northern blot analyses and deep sequencing}

Small RNA Northern blots and probe labeling were performed as previously described (Pall and Hamilton 2008; Perez et al. 2009). Probes used include the following: anti-miR-124: 5'-TGGCATT CACCGCGTGCCTTAA-3', anti-miR-122: 5' -CAAACACCATTG TCACACTCCA-3', anti-miR-93: 5' -CTACCTGCACGAACAGCAC TTTG-3', and anti-U6: 5'-GCCATGCTAATCTTCTCTGTATC-3' . 
For deep sequencing analysis, small RNA libraries were generated as previously described (Pfeffer et al. 2005). Total RNA from mocktreated or MEFS infected for $24 \mathrm{~h}$ with rSINV or rSINV124 (MOI = 2) was harvested and small RNA species were separated on a $12 \%$ denaturing tris-urea gel, isolated, purified, and amplified as previously described (Shapiro et al. 2010). Amplified small RNA species were run on an Illumina GA llx HiSeq 2000 sequencing platform. Copy numbers were estimated on miR-93 and Mcm7 expression, which is expressed at $1.00 \times 10^{4}$ to $1.00 \times 10^{5}$ molecules per cell in murine fibroblasts (Tye 1999).

\section{Immunoprecipitation and Western blot}

IPs were performed in BHKs. Cells were transfected with $12 \mu \mathrm{g}$ of Flag-epitope tagged AGO2 or GFP (addgene Cat's 19888 or 22612, respectively) and subsequently mock-treated or infected with indicated rSINVs $($ MOI $=2$ ). Protein was harvested $16 \mathrm{hpi}$ and immunoprecipitated with Protein-G-PLUS agarose (Santa Cruz Biotechnology) and $10 \mu \mathrm{g}$ of anti-Flag (Sigma) for $24 \mathrm{~h}$ at $4^{\circ} \mathrm{C}$. Beads were washed and run on a Western blot, or washed and RNA was extracted for Northern blot analysis. Western blots were performed as previously described (Schmid et al. 2010). Antibodies specific to Flag (Sigma), Sindbis (gift from Dr. Diane Griffin), and actin (Thermo Scientific) were all used at a concentration of $1 \mu \mathrm{g} / \mathrm{mL}$.

\section{Luciferase assay and PTS}

BHKs were transfected with (1) Gaussia luciferase containing four tandem perfect miR-122 target sites (GLuc122T), (2) untargeted firefly luciferase, and (3) a plasmid expressing miR-122 (p122), miR-124 (p124), or a scrambled hairpin (p-). Fourteen hours posttransfection, cells were mock-treated or infected with rSINVs at an MOI of 3. Four hours post-infection, inoculum was removed and media was replaced with serum free DMEM. Luciferase expression was analyzed 8 hpi and the levels of targeted Gaussia luciferase were normalized to the untargeted control. Percent luciferase repression was normalized to control WT infection. $P$-values for GLuc122T, as compared with mock or rSINV, are as follows: p122 $(P=2.1 \times$ $\left.10^{-6}\right), \mathrm{p} 124(P=0.13), \operatorname{rSINV} 122\left(P=2.1 \times 10^{-2}\right), \mathrm{rSINV} 124$ $(P=0.46)$, and rSINVdbl $\left(P=7.3 \times 10^{-4}\right) . P$-value for rSINVdbl, as compared against rSINV122, is 0.84 .

\section{Immunofluorescence and fluorescent in situ hybridization}

Cells were fixed on glass coverslips by incubating with $4 \%$ paraformaldehyde (PFA) for $10 \mathrm{~min}$ at $4^{\circ} \mathrm{C}$ and subsequently washed twice with phosphate buffered saline (PBS). Cells were permeabilized with $0.5 \%$ NP40 detergent in PBS for $10 \mathrm{~min}$ and washed two additional times at room temperature (RT). For in situ samples, cells were blocked with $0.5 \%$ bovine albumin solution (BSA) in PBS (PBB) for $30 \mathrm{~min}$ at RT and incubated in anti-polyclonal PR8 (a kind gift from Dr. Peter Palese) and anti-polyclonal SINV (a kind gift from Dr. Diane Griffin) diluted at 1:500 in PBB at RT for $2 \mathrm{~h}$. For Drosha-specific immunohistochemistry, cells were blocked with $1 \%$ PBB for $30 \mathrm{~min}$ at RT and incubated in antipolyclonal Drosha (abcam) diluted 1:25 in PBB and anti-monoclonal SINV (ATCC) diluted 1:500 in $0.5 \%$ PBB for $2 \mathrm{~h}$ at RT. Following four washes in $0.5 \% \mathrm{PBB}$, cells were incubated at RT with secondary antibody, Dylight488 (Jackson ImmunoResearch) and/ or Rhodamine Red (Jackson ImmunoResearch) at 1:750 for $1 \mathrm{~h}$ and then washed twice with $0.5 \%$ PBB. Subsequent in situ hybridization was carried out as described elsewhere (Wilkinson and Nieto 1993; Wienholds et al. 2005) using digoxigenin-11-UTP (Roche) labeled DNA probe directed against pri-miR-124 (5'-CCTTCCTAACTTCTCTCGGATGTCC-3'). Hybridized probes were visualized using Rhodamine-conjugated anti-DIG (Roche). All samples were incubated with Hoechst 33342 dye (Invitrogen) at 1:10,000 in PBB for 15 min, washed four times, and coverslips were mounted on glass slides with Prolong Gold Antifade (Invitrogen). Images were captured with the Olympus IX70 microscope at $60 \times$ magnification or on a Leica SP5 DM at $63 \times$ magnification.

\section{Semiquantitative reverse transcriptase-PCR}

One microgram of total RNA was used in first strand synthesis reverse transcriptase-PCR using oligo-DT primers. SINV-specific $\mathrm{nsP} 1$ primers and actin-specific primers were used and PCR products run on a $1 \%$ agarose gel.

\section{Quantification of autoradiograms}

Bands on autoradiograms were quantified using Quantity One rectangular volume analysis function. All processing events were analyzed from three independent experiments. Processing dependency was calculated as fold change over processing in WT MEFs. $P$-values for pri-miRNA to pre-miRNA processing are as follows: Drosha $\left(P=2.1 \times 10^{-4}\right)$, DGCR8 $(P=0.037)$, Dicer $(P=0.92)$, TRBP $(P=0.95)$, PACT $(P=0.37)$, and AGO2 $(P=54) . P$-values for pri-miRNA to mature miRNA processing are as follows: Drosha $\left(P=5.0 \times 10^{-6}\right)$, DGCR8 $(P=0.001)$, Dicer $(P=0.00)$, TRBP $(P=$ $\left.5.8 \times 10^{-2}\right)$, PACT $(P=0.50)$, and AGO2 $(P=73)$. $P$-values for pri-miRNA to mature miRNA processing are as follows: Drosha $(P=$ $\left.2.8 \times 10^{-3}\right)$, DGCR8 $\left(P=3.7 \times 10^{-3}\right)$, Dicer $(P=0.00)$, TRBP $(P=$ $\left.7.1 \times 10^{-2}\right)$, PACT $\left(P=9.6 \times 10^{-2}\right)$, and AGO2 $(P=0.39)$.

\section{Statistical analysis}

Statistical analysis was performed on indicated samples using a two-tailed, unpaired Student's T-test. Data are considered significant if $P$-value is $<0.05$. Linear regression analysis was performed where indicated.

\section{SUPPLEMENTAL MATERIAL}

Supplemental material is available for this article.

\section{ACKNOWLEDGMENTS}

This material is based upon work supported in part by the US Army Research Laboratory and the US Army Research Office under grant number W911NF-07-R-0003-4. R.A.L. is supported by the NYU-MSSM Mechanisms of Virus-Host Interactions National Institutes of Health T32 training grant (no. AI07647-09). B.R.t.O. is supported in part by the Pew Charitable Trust and the Burroughs Wellcome Fund. We thank Drs. Alexander Tarakhovsky (Rockefeller University) and Donal O'Carroll (EMBL, Monterotondo, Italy) for Dicer1 $1^{-/-}$and Eif2c2 ${ }^{-/-}$fibroblasts; Dr. Dan Littman (NYU) for providing Rnasen ${ }^{\text {fl } f l}$ fibroblasts; Dr. Robert Blelloch (UCSF) 
for $D g c r 8^{f l / f l}$ fibroblasts; Dr. Anne Gatignol (McGill University) for Tarbp ${ }^{-/-}$fibroblasts; and Dr. Ganes C. Sen (Cleveland Clinic) for $\mathrm{Prkra}^{-/-}$fibroblasts. The polyclonal SINV and Influenza A antibodies were kind gifts from Dr. Diane Griffin (Johns Hopkins University) and Dr. Peter Palese (Mount Sinai School of Medicine), respectively.

Author contributions: J.S.S. designed and performed the experiments and wrote the manuscript. R.A.L. and A.M.P. performed experiments. B.R.t.O. oversaw the work and edited the final version of the manuscript.

Received January 3, 2012; accepted May 4, 2012.

\section{REFERENCES}

Babiarz JE, Ruby JG, Wang Y, Bartel DP, Blelloch R. 2008. Mouse ES cells express endogenous shRNAs, siRNAs, and other Microprocessor-independent, Dicer-dependent small RNAs. Genes Dev 22: 2773-2785.

Babiarz JE, Hsu R, Melton C, Thomas M, Ullian EM, Blelloch R. 2011. A role for noncanonical microRNAs in the mammalian brain revealed by phenotypic differences in Dgcr8 versus Dicer1 knockouts and small RNA sequencing. RNA 17: 14891501.

Baccarini A, Chauhan H, Gardner TJ, Jayaprakash AD, Sachidanandam R, Brown BD. 2011. Kinetic analysis reveals the fate of a microRNA following target regulation in mammalian cells. Curr Biol 21: 369376.

Bartel DP. 2009. MicroRNAs: Target recognition and regulatory functions. Cell 136: 215-233.

Bazzini AA, Lee MT, Giraldez AJ. 2012. Ribosome profiling shows that miR-430 reduces translation before causing mRNA decay in zebrafish. Science 336: 233-237.

Berezikov E, Chung WJ, Willis J, Cuppen E, Lai EC. 2007. Mammalian mirtron genes. Mol Cell 28: 328-336.

Bernstein E, Caudy AA, Hammond SM, Hannon GJ. 2001. Role for a bidentate ribonuclease in the initiation step of RNA interference. Nature 409: 363-366.

Bohnsack MT, Czaplinski K, Gorlich D. 2004. Exportin 5 is a RanGTP-dependent dsRNA-binding protein that mediates nuclear export of pre-miRNAs. RNA 10: 185-191.

Cai X, Hagedorn CH, Cullen BR. 2004. Human microRNAs are processed from capped, polyadenylated transcripts that can also function as mRNAs. RNA 10: 1957-1966.

Cheloufi S, Dos Santos CO, Chong MM, Hannon GJ. 2010. A dicerindependent miRNA biogenesis pathway that requires Ago catalysis. Nature 465: 584-589.

Chendrimada TP, Gregory RI, Kumaraswamy E, Norman J, Cooch N, Nishikura K, Shiekhattar R. 2005. TRBP recruits the Dicer complex to Ago2 for microRNA processing and gene silencing. Nature 436: 740-744.

Chong MM, Zhang G, Cheloufi S, Neubert TA, Hannon GJ, Littman DR. 2010. Canonical and alternate functions of the microRNA biogenesis machinery. Genes Dev 24: 1951-1960.

Cifuentes D, Xue H, Taylor DW, Patnode H, Mishima Y, Cheloufi S, Ma E, Mane S, Hannon GJ, Lawson ND, et al. 2010. A novel miRNA processing pathway independent of Dicer requires Argonaute2 catalytic activity. Science 328: 1694-1698.

Czech B, Hannon GJ. 2011. Small RNA sorting: Matchmaking for Argonautes. Nat Rev Genet 12: 19-31.

Denli AM, Tops BB, Plasterk RH, Ketting RF, Hannon GJ. 2004. Processing of primary microRNAs by the Microprocessor complex. Nature 432: 231-235.

Filipowicz W, Bhattacharyya SN, Sonenberg N. 2008. Mechanisms of post-transcriptional regulation by microRNAs: Are the answers in sight? Nat Rev Genet 9: 102-114.
Gantier MP, McCoy CE, Rusinova I, Saulep D, Wang D, Xu D, Irving AT, Behlke MA, Hertzog PJ, Mackay F, et al. 2011. Analysis of microRNA turnover in mammalian cells following Dicer1 ablation. Nucleic Acids Res 39: 5692-5703.

Gregory RI, Yan KP, Amuthan G, Chendrimada T, Doratotaj B, Cooch N, Shiekhattar R. 2004. The Microprocessor complex mediates the genesis of microRNAs. Nature 432: 235-240.

Grishok A, Pasquinelli AE, Conte D, Li N, Parrish S, Ha I, Baillie DL, Fire A, Ruvkun G, Mello CC. 2001. Genes and mechanisms related to RNA interference regulate expression of the small temporal RNAs that control C. elegans developmental timing. Cell 106: $23-$ 34.

Haase AD, Jaskiewicz L, Zhang H, Laine S, Sack R, Gatignol A, Filipowicz W. 2005. TRBP, a regulator of cellular PKR and HIV-1 virus expression, interacts with Dicer and functions in RNA silencing. EMBO Rep 6: 961-967.

Han J, Lee Y, Yeom KH, Nam JW, Heo I, Rhee JK, Sohn SY, Cho Y, Zhang BT, Kim VN. 2006. Molecular basis for the recognition of primary microRNAs by the Drosha-DGCR8 complex. Cell 125: 887-901.

Han J, Pedersen JS, Kwon SC, Belair CD, Kim YK, Yeom KH, Yang WY, Haussler D, Blelloch R, Kim VN. 2009. Posttranscriptional crossregulation between Drosha and DGCR8. Cell 136: 75-84.

Hutvagner G, McLachlan J, Pasquinelli AE, Balint E, Tuschl T, Zamore PD. 2001. A cellular function for the RNA-interference enzyme Dicer in the maturation of the let-7 small temporal RNA. Science 293: 834-838.

Isken O, Maquat LE. 2007. Quality control of eukaryotic mRNA: Safeguarding cells from abnormal mRNA function. Genes Dev 21: 1833-1856.

Kadener S, Rodriguez J, Abruzzi KC, Khodor YL, Sugino K, Marr MT II, Nelson S, Rosbash M. 2009. Genome-wide identification of targets of the drosha-pasha/DGCR8 complex. RNA 15: 537-545.

Ketting RF, Fischer SE, Bernstein E, Sijen T, Hannon GJ, Plasterk RH. 2001. Dicer functions in RNA interference and in synthesis of small RNA involved in developmental timing in C. elegans. Genes Dev 15: 2654-2659.

Khvorova A, Reynolds A, Jayasena SD. 2003. Functional siRNAs and miRNAs exhibit strand bias. Cell 115: 209-216.

Kim VN, Han J, Siomi MC. 2009. Biogenesis of small RNAs in animals. Nat Rev Mol Cell Biol 10: 126-139.

Lagos-Quintana M, Rauhut R, Lendeckel W, Tuschl T. 2001. Identification of novel genes coding for small expressed RNAs. Science 294: 853-858.

Lagos-Quintana M, Rauhut R, Yalcin A, Meyer J, Lendeckel W, Tuschl T. 2002. Identification of tissue-specific microRNAs from mouse. Curr Biol 12: 735-739.

Langlois RA, Shapiro JS, Pham AM, tenOever BR. 2012. In vivo delivery of cytoplasmic RNA virus-derived miRNAs. Mol Ther 20: 367-375.

Lee Y, Jeon K, Lee JT, Kim S, Kim VN. 2002. MicroRNA maturation: Stepwise processing and subcellular localization. EMBO J 21: 4663-4670.

Lee Y, Kim M, Han J, Yeom KH, Lee S, Baek SH, Kim VN. 2004. MicroRNA genes are transcribed by RNA polymerase II. EMBO J 23: 4051-4060.

Lee Y, Hur I, Park SY, Kim YK, Suh MR, Kim VN. 2006. The role of PACT in the RNA silencing pathway. EMBO J 25: 522-532.

Lim LP, Glasner ME, Yekta S, Burge CB, Bartel DP. 2003. Vertebrate microRNA genes. Science 299: 1540. doi: 10.1126/science.1080372.

Lund E, Guttinger S, Calado A, Dahlberg JE, Kutay U. 2004. Nuclear export of microRNA precursors. Science 303: 95-98.

O'Carroll D, Mecklenbrauker I, Das PP, Santana A, Koenig U, Enright AJ, Miska EA, Tarakhovsky A. 2007. A Slicer-independent role for Argonaute 2 in hematopoiesis and the microRNA pathway. Genes Dev 21: 1999-2004.

Okamura K, Hagen JW, Duan H, Tyler DM, Lai EC. 2007. The mirtron pathway generates microRNA-class regulatory RNAs in Drosophila. Cell 130: 89-100. 
Pall GS, Hamilton AJ. 2008. Improved Northern blot method for enhanced detection of small RNA. Nat Protoc 3: 1077-1084.

Park JE, Heo I, Tian Y, Simanshu DK, Chang H, Jee D, Patel DJ, Kim VN. 2011. Dicer recognizes the $5^{\prime}$ end of RNA for efficient and accurate processing. Nature 475: 201-205.

Patel RC, Sen GC. 1998. PACT, a protein activator of the interferoninduced protein kinase, PKR. EMBO J 17: 4379-4390.

Perez JT, Pham AM, Lorini MH, Chua MA, Steel J, tenOever BR. 2009. MicroRNA-mediated species-specific attenuation of influenza A virus. Nat Biotechnol 27: 572-576.

Perez JT, Varble A, Sachidanandam R, Zlatev I, Manoharan M, Garcia-Sastre A, tenOever BR. 2010. Influenza A virus-generated small RNAs regulate the switch from transcription to replication. Proc Natl Acad Sci 107: 11525-11530.

Pfeffer S, Sewer A, Lagos-Quintana M, Sheridan R, Sander C, Grasser FA, van Dyk LF, Ho CK, Shuman S, Chien M, et al. 2005. Identification of microRNAs of the herpesvirus family. Nat Methods 2: 269-276.

Rouha H, Thurner C, Mandl CW. 2010. Functional microRNA generated from a cytoplasmic RNA virus. Nucleic Acids Res 38: 8328-8337.

Ruby JG, Jan CH, Bartel DP. 2007. Intronic microRNA precursors that bypass Drosha processing. Nature 448: 83-86.

Saunders LR, Barber GN. 2003. The dsRNA binding protein family: Critical roles, diverse cellular functions. FASEB J 17: 961-983.

Schmid S, Mordstein M, Kochs G, Garcia-Sastre A, tenOever BR. 2010. Transcription factor redundancy ensures induction of the antiviral state. J Biol Chem 285: 42013-42022.

Schwarz DS, Hutvagner G, Du T, Xu Z, Aronin N, Zamore PD. 2003. Asymmetry in the assembly of the RNAi enzyme complex. Cell 115: 199-208.
Shapiro JS, Varble A, Pham AM, tenOever BR. 2010. Noncanonical cytoplasmic processing of viral microRNAs. RNA 16: 2068-2074.

Tang X, Zhang Y, Tucker L, Ramratnam B. 2010. Phosphorylation of the RNase III enzyme Drosha at Serine300 or Serine302 is required for its nuclear localization. Nucleic Acids Res 38: 6610-6619.

Tye BK. 1999. MCM proteins in DNA replication. Annu Rev Biochem 68: 649-686.

Varble A, Chua MA, Perez JT, Manicassamy B, Garcia-Sastre A, tenOever BR. 2010. Engineered RNA viral synthesis of microRNAs. Proc Natl Acad Sci 107: 11519-11524.

Wienholds E, Kloosterman WP, Miska E, Alvarez-Saavedra E, Berezikov E, de Bruijn E, Horvitz HR, Kauppinen S, Plasterk RH. 2005. MicroRNA expression in zebrafish embryonic development. Science 309: 310-311.

Wilkinson DG, Nieto MA. 1993. Detection of messenger RNA by in situ hybridization to tissue sections and whole mounts. Methods Enzymol 225: 361-373.

Yang JS, Maurin T, Robine N, Rasmussen KD, Jeffrey KL, Chandwani R, Papapetrou EP, Sadelain M, O'Carroll D, Lai EC. 2010. Conserved vertebrate mir-451 provides a platform for Dicerindependent, Ago2-mediated microRNA biogenesis. Proc Natl Acad Sci 107: 15163-15168.

Yi R, Qin Y, Macara IG, Cullen BR. 2003. Exportin-5 mediates the nuclear export of pre-microRNAs and short hairpin RNAs. Genes Dev 17: 3011-3016.

Zeng Y, Cullen BR. 2004. Structural requirements for pre-microRNA binding and nuclear export by Exportin 5. Nucleic Acids Res 32: 4776-4785.

Zhong J, Peters AH, Lee K, Braun RE. 1999. A double-stranded RNA binding protein required for activation of repressed messages in mammalian germ cells. Nat Genet 22: 171-174. 

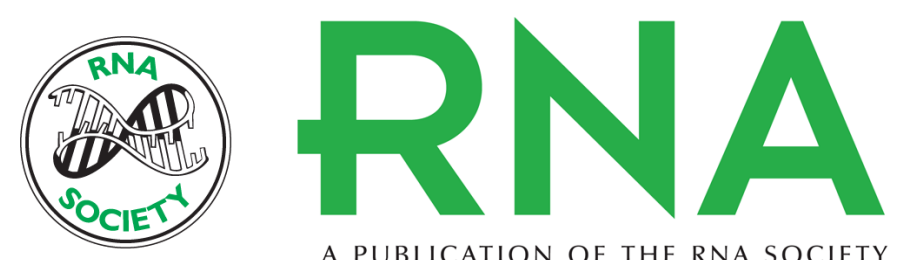

A PUBLICATION OF THE RNA SOCIETY

\section{Evidence for a cytoplasmic microprocessor of pri-miRNAs}

Jillian S. Shapiro, Ryan A. Langlois, Alissa M. Pham, et al.

RNA 2012 18: 1338-1346 originally published online May 25, 2012

Access the most recent version at doi:10.1261/rna.032268.112

Supplemental

Material

References

\section{License}

Email Alerting Service
http://rnajournal.cshlp.org/content/suppl/2012/05/07/rna.032268.112.DC1

This article cites 59 articles, 27 of which can be accessed free at: http://rnajournal.cshlp.org/content/18/7/1338.full.html\#ref-list-1 